\title{
How Do Histopathological Findings Relate To Cervical Lymph Node Metastasis In Laryngeal Cancer? A Retrospective Study And Literature Review
}

\author{
${ }^{1}$ Seyda Belli MD., ${ }^{2}$ Metin Yıldırım MD., ${ }^{3}$ Funda Emre Kaya MD., ${ }^{4}$ Tolga Bilece MD., ${ }^{1}$ Mehmet Faruk Oktay MD \\ 1 Bagcilar Training and Research Hospital, Otorhinolaryngology Dept., Istanbul- Turkey - ORCID ID: 0000-0002-9132-4419 \\ 2 Gumushane State Hospital, Otorhinolaryngology Department, Istanbul- Turkey - ORCID ID: 0000-0002-0199-3556 \\ 3 Bagcilar Training and Research Hospital, Pathology Department, Istanbul- Turkey - ORCID ID: 0000-0002-8822-0723 \\ 4 Bakırkoy Training and Research Hospital, Otorhinolaryngology Department, Istanbul- Turkey - ORCID ID: 0000-0002-3755-9559 \\ 1 Bagcilar Training and Research Hospital, Otorhinolaryngology Dept., Istanbul- Turkey - ORCID ID: 0000-0001-5708-4813
}

\begin{abstract}
Purpose: This study aimed to elucidate how histopathological findings relate to the existence of metastases in lymph nodes in a cohort of surgical cases with squamous cell carcinoma of the larynx.

Material and Methods: A cohort of cases from the ENT department, who had partial or total laryngectomy and dissection of the neck in the period spanning January 2008 to June 2017 were evaluated retrospectively. 150 cases were deemed appropriate for inclusion in the study. The histopathological notes and clinical findings of these cases were compared to each other.
\end{abstract}

Findings: The glottic group had lower levels of lympho- vascular invasion $(p<0.05)$. Tumours staged at T3 or T4 level or endophytic in subtype were, however, more likely to have lymphovascular invasive features $(p<0.05)$. For neoplasms with a high degree of differentiation, it was less frequent to observe invasion of lymphatics, metastasis to the cervical nodes or invasion beyond the capsule $(p<0.05)$. Perineural invasion was not associated with a greater risk of the neoplasm metastasizing to the cervical lymphovasculature, but invasion of the lymphatics did signal an increase in metastasis $(p<0.05)$.

Conclusion: Cervical lymphatic metastasis of squamous cell carcinoma of the larynx has a high degree of correlation with histopathological grading.

Key Words: Laryngeal cancer, perineural invasion, lymphovascular invasion, cervical lymphatic metastasis

\section{Introduction}

Squamous cell carcinoma of the larynx is amongst the most frequently encountered of head and neck neoplasms associated with raised mortality and unfavourable outcome. The rate of new neoplasms of this type diagnosed exceeds 12,500 per annum and annual mortality from the condition is 3,560. Therapy, diagnosis and prevention can only improve through deeper knowledge of the complex natural history of the tumour (1). Smoking, alcohol use and HPV are known risk factors. Laryngeal carcinoma is subdivided into four principal divisions on the basis of anatomical site: supraglottic, glottic, subglottic and transglottic $(1,2)$.

Despite the advances in treatment brought about by organ-sparing treatment regimens, there has been no improvement in survival from laryngeal SCC. If the factors that affect prognosis can be understood, improved treatment protocols may be able to be developed. The principal factor determining a worse prognosis in head and neck ma-
Correspondence: Seyda Belli MD,

Bagcilar Training and Research Hospital, Otorhinolaryngology Department, Istanbul- Turkey e-mail: drseydabelli@gmail.com
Online available at: www.entupdates.org

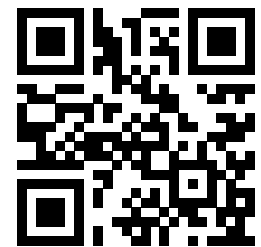


lignancies is the existence of metastasis to the lymphatics. Despite this, staging the nodes only $(\mathrm{pN}+)$ fails to predict prognosis in a consistent fashion. Thus, knowing what additional actors influence prognosis in $\mathrm{pN}+$ cases will allow better treatment planning, including the use of adjuvant therapy modalities (3). There has been an extensive research effort aiming to elucidate markers of prognosis for carcinoma of the larynx. Indeed, there has been a strong focus on histopathology as a way to realise such markers. NO neck management is advocated when the probability of ocular neck metastases is more than $20 \%$. Local recurrence of laryngeal SCC is recognised as a key factor in prognosis. Histopathological grading of the degree to which the carcinoma is differentiated has also been suggested as prognostically useful. There are also associations between the presence of tumour outside the capsule $(\mathrm{N}+$ neoplasm), the amount of keratin pearl formation, perineural invasion or small vasculature involvement and a worsened prognosis. These histopathological features need to be recorded in all cases (4).

Just as with other neoplasms of the head and neck region, there are three main growth patterns in laryngeal carcinoma: exophytic, endophytic or combined. It is usual for the exophytic type neoplasms, which grow outwards in a cauliflower-like form, to be detected at an earlier stage and to have a correspondingly better associated outcome. The endophytic subtype grows inwards, invading the basal lamina and only becoming symptomatic at a late stage. Having breached the basal lamina, the neoplasm then infiltrates the lymphovasculature situated in the lamina propria (5).

If there are neoplastic cells found within the three layers of the neural sheath (epi-, peri- or endoneurium) (6), perineural invasion (PNI) is diagnosed. Extension along the neural sheath may occur both in a proximal and distal direction. The usual pattern is for invasion to occur initially towards the terminal end of the nerve and then track backwards to bigger neural structures (7). It is frequently difficult for the histopathologist to be sure whether PNI has taken place. Whilst the nerve may become entirely encased in neoplastic cells, on occasion, a single neoplastic cell found perineurally is the only indicator of PNI on a routine section. Since section thickness is usually $5 \mathrm{mi}-$ crons, to examine to a depth of $1 \mathrm{~mm}$ would require 200 sections to be cut (8), and since this is impractical, there is a high chance of routine sectioning missing PNI.

Vascular invasion occurs when malignant cells can be demonstrated within vessels (whether lympho- or haemo- vascular), and adhering to the vessel lining or to thrombotic lesions in the vein (9). A number of researchers have reported that vascular invasion is associated with greater likelihood of regional metastasis and a worsened clinical outlook (10).

The present study aimed to evaluate any relationship between histopathological grading and occurrence of metastasis to the neck lymph glands, a key factor in the prognosis for laryngeal SCC.

\section{Materialand Methods}

Ethical approval was granted at the outset of the study. A retrospective review was undertaken on 223 cases attending ENT from January 2008 to June 2017 who were diagnosed with SCC of the larynx. In 73 cases, the records were excluded from the review. In these cases, rescue operations or neck dissection had occurred, or the diagnosis was of oesophageal carcinoma, either hypopharyngeal or cervical. The remaining 150 records were from individuals who underwent partial or complete laryngectomy and neck dissection. Patients were evaluated retrospectively for the presence of lymphatic metastasis, extracapsular extension, $\mathrm{T}$ and $\mathrm{N}$ stages, tumour location, pattern of tumour spread, histopathological tumour type, the development of perineural invasion and lymphovascular invasion. The data from the review were used to compare the association of particular variables, and the level of statistical significance was determined.

The NCSS (Number Cruncher Statistical System) 2007 Statistical Software (Utah, USA) application was used for statistical analysis. Descriptive statistical values were obtained for means and standard deviations. The data were checked for a normal distribution using the Kolmogorov-Smirnov test. Groups were compared pairwise using the independent samples t test. Qualitative values were compared with the Fisher exact and Fisher Freeman Halton Exact tests. Causality was ascertained between variables by a logistic regression technique. A value of $\mathrm{p}<0.05$ was taken to indicate statistical significance.

A post hoc power analysis revealed that the lowest power lay between 0.238 and 0.721 and overall power lay between 0.394 and 1.000 .

\section{Results}

One hundred and fifty patients (147 males and 3 females) participated in the study. The mean age at the onset of the study was 59.8+/-5.6. Supraglottic tumours were de- 
tected in 41 patients $(27.3 \%)$, transglottic tumours in 94 patients $(62.6 \%)$ and glottic tumours in 15 patients $(10 \%)$. In no case was any isolated subglottic tumour seen. The histopathological type was "moderately differentiated" in 76 patients (50.6\%), "well differentiated" in 35 patients (23.3\%) and "poorly differentiated" in 39 patients (26\%). Laryngeal SCC was classified as exophytic, endophytic or mixed type depending on the pattern of growth. The exophytic growth pattern was observed in 87 (58\%) patients, endophytic growth in $54(36 \%)$ and mixed type growth in $9(6 \%)$ patients. Seven patients $(4.6 \%)$ had perineural invasion, 41 patients (27.3\%) had lymphovascular invasion, and 6 patients (4\%) had both perineural and lymphovascular invasion. Cervical lymphatic metastasis was not detected in 96 patients. Fifty-four (36\%) of the patients had one or more lymphatic metastases in the neck area. Extracapsular extension was seen in 23 lymph nodes (15.3\%).

The study looked at any relationship between $\mathrm{T}$ stage and perineural invasion, lymphovascular invasion, cervical lymphatic metastasis or extracapsular invasion. Tumours staged T3 and T4 were significantly more likely to show evidence of lymphovascular infiltration than the other types $(\mathrm{p}=0.005)$, and, in addition, such tumours were associated at the level of statistical significance $(\mathrm{p}=0.035)$ with higher $\mathrm{N}$ stage than other tumours. T-stage, perineural invasion and extracapsular spread were not related at the level of statistical significance ( $p>0.05)$. T-stage (early to advanced) had a statistically significant relationship $(\mathrm{p}<0.0001)$ with the anatomical location of the tumour (see Table 1).

The study also investigated any relationship between metastases in the cervical lymph glands and perineural or lymphovascular infiltration. $\mathrm{N}$-stage and the presence of perineural infiltration were not related at the level of statistical significance $(\mathrm{p}=0.425)$. However, $\mathrm{N}$-stage was associated with invasion of the lymphatics. In cases where lymphovascular invasion was demonstrated, there was a significant association with a higher $\mathrm{N}$-stage $(\mathrm{p}=0.0001)$. (See Table 2).

Table 1: Distribution of cases

\begin{tabular}{|c|c|c|c|c|c|c|}
\hline & \multicolumn{6}{|c|}{ T stage (early-advanced) } \\
\hline & & \multicolumn{2}{|c|}{ Early (T1-T2) } & \multicolumn{2}{|c|}{ Advanced (T3-T4) } & \multirow[b]{2}{*}{$\mathbf{p}$} \\
\hline & & $\mathrm{n}$ & $\%$ & $\mathbf{n}$ & $\%$ & \\
\hline \multirow[t]{2}{*}{$\mathrm{N}$ stage } & NO & 51 & 72.86 & 45 & 56.25 & \multirow{2}{*}{0.035} \\
\hline & $\mathrm{N}+$ & 19 & 27.14 & 35 & 43.75 & \\
\hline \multirow[t]{2}{*}{ Perineural invasion } & Negative & 66 & 94.29 & 71 & 88.75 & \multirow{2}{*}{0.229} \\
\hline & Positive & 4 & 5.71 & 9 & 11.25 & \\
\hline \multirow[t]{2}{*}{ Lymphovascular invasion } & Negative & 56 & 80.00 & 47 & 58.75 & \multirow{2}{*}{0.005} \\
\hline & Positive & 14 & 20.00 & 33 & 41.25 & \\
\hline \multirow[t]{2}{*}{ Extracapsular invasion } & Negative & 63 & 90.00 & 64 & 80.00 & \multirow{2}{*}{0.090} \\
\hline & Positive & 7 & 10.00 & 16 & 20.00 & \\
\hline \multirow[t]{3}{*}{ Tumor localization } & Glottic & 14 & 20.00 & 1 & 1.25 & \multirow{3}{*}{ pi 0.0001} \\
\hline & Supraglottic & 24 & 34.29 & 17 & 21.25 & \\
\hline & Transglottic & 32 & 45.71 & 62 & 77.50 & \\
\hline \multirow[t]{3}{*}{ Histologic differentisation } & Poorly & 14 & 20.00 & 25 & 31.25 & \multirow{3}{*}{0.158} \\
\hline & Moderate & 36 & 51.43 & 40 & 50.00 & \\
\hline & Well & 20 & 28.57 & 15 & 18.75 & \\
\hline \multirow[t]{3}{*}{ Growth pattern } & Exophytic & 5 & 7.14 & 4 & 5.00 & \multirow{3}{*}{0.281} \\
\hline & Endophytic & 36 & 51.43 & 51 & 63.75 & \\
\hline & Mixed pattern & 29 & 41.43 & 25 & 31.25 & \\
\hline
\end{tabular}


Table 2: The relationship between perineural and lymphovascular invasion with cervical node metastasis.

\begin{tabular}{|c|c|c|c|c|c|c|}
\hline & & \multicolumn{2}{|c|}{ Perineural Invasion (-) } & \multicolumn{2}{|c|}{ Perineural Invasion (+) } & $\mathbf{P}$ \\
\hline & NO & 89 & $65,0 \%$ & 7 & $53,9 \%$ & \multirow{2}{*}{0,425} \\
\hline N Stage & $\mathrm{N}+$ & 48 & $35,0 \%$ & 6 & $46,1 \%$ & \\
\hline I & & \multicolumn{2}{|c|}{ Lymphovascular Invasion (-) } & \multicolumn{2}{|c|}{ Lymphovascular Invasion (+) } & $\mathbf{P}$ \\
\hline & No & 90 & $87,4 \%$ & 6 & $12,8 \%$ & \multirow{2}{*}{0,0001} \\
\hline N Stage & $\mathrm{N}+$ & 13 & $12,6 \%$ & 41 & $87,2 \%$ & \\
\hline
\end{tabular}

Table 3: The affect of tumor location to the perineural and lymphovascular invasion.

\begin{tabular}{|c|c|c|c|c|c|c|c|c|}
\hline \multicolumn{9}{|c|}{ Tumor Location } \\
\hline \multirow[b]{2}{*}{ Perineural İnvasion } & \multirow[b]{2}{*}{$(-)$} & \multicolumn{2}{|c|}{ Glottic } & \multicolumn{2}{|c|}{ Supraglottic } & \multicolumn{2}{|c|}{ Transglottic } & \\
\hline & & 15 & $100,0 \%$ & 38 & $92,7 \%$ & 84 & $89,3 \%$ & \\
\hline & $(+)$ & 0 & $0,0 \%$ & 3 & $7,3 \%$ & 10 & $10,7 \%$ & 0,372 \\
\hline \multirow{2}{*}{$\begin{array}{l}\text { Lymphovascular İnva- } \\
\text { sion }\end{array}$} & $(-)$ & 14 & $93,3 \%$ & 24 & $58,5 \%$ & 65 & $69,1 \%$ & \\
\hline & $(+)$ & 1 & $6,7 \%$ & 17 & $41,5 \%$ & 29 & $30,9 \%$ & 0,045 \\
\hline
\end{tabular}

Table 4: The affect of tumor histological type to the perineural or lymphovascular invasion, nodal metastasis, tumor location and extracapsular invasion

\begin{tabular}{|c|c|c|c|c|c|c|c|c|}
\hline \multicolumn{2}{|c|}{ Histological type } & \multicolumn{2}{|c|}{ Well differentiated } & \multicolumn{2}{|c|}{$\begin{array}{c}\text { Moderate } \\
\text { differentiated }\end{array}$} & \multicolumn{2}{|c|}{ Poorly differentiated } & \multirow{2}{*}{$\begin{array}{c}p \\
0.381\end{array}$} \\
\hline \multirow[t]{3}{*}{ Location } & glottic & 4 & $26.67 \%$ & 8 & $53.33 \%$ & 3 & $20.00 \%$ & \\
\hline & supraglottic & 5 & $12.20 \%$ & 24 & $58.54 \%$ & 12 & $29.27 \%$ & \\
\hline & transglottic & 26 & $27.66 \%$ & 44 & $46.81 \%$ & 24 & $25.53 \%$ & \\
\hline \multirow[t]{2}{*}{ Lymphovascular invasion } & Positive & 5 & $14.29 \%$ & 24 & $31.58 \%$ & 18 & $46.15 \%$ & 0.013 \\
\hline & Negative & 30 & $85.71 \%$ & 52 & $68.42 \%$ & 21 & $53.85 \%$ & \\
\hline \multirow{2}{*}{ Perineural } & Positive & 6 & $17.14 \%$ & 3 & $3.95 \%$ & 4 & $10.26 \%$ & 0.066 \\
\hline & Negative & 29 & $82.86 \%$ & 73 & $96.05 \%$ & 35 & $89.74 \%$ & \\
\hline \multirow[t]{2}{*}{ N stage } & No & 29 & $82.86 \%$ & 46 & $60.53 \%$ & 21 & $53.85 \%$ & 0.023 \\
\hline & $\mathrm{N}+$ & 6 & $17.14 \%$ & 30 & $39.47 \%$ & 18 & $46.15 \%$ & \\
\hline \multirow[t]{2}{*}{ Extracapsuler Invasion } & Positive & 1 & $2.86 \%$ & 11 & $14.47 \%$ & 11 & $28.21 \%$ & 0.01 \\
\hline & Negative & 34 & $97.14 \%$ & 65 & $85.53 \%$ & 28 & $71.79 \%$ & \\
\hline
\end{tabular}

The study also examined the relationship between site of the tumour (glottic, supra- or trans-glottic) and the presence of invasive features (perineural or lymphovascular), but concluded no such relationship existed ( $\mathrm{p}=0.372)$. However, glottic tumours were associated with a lower risk of lymphovascular infiltration $(\mathrm{p}<0.05)$ (see Table 3$)$.

Tumour site and histopathological type were not associated at the level of statistical significance $(\mathrm{p}=0.381)$. The researchers evaluated the relationship between histopathological tumour typing and invasion (perineural or lymphovascular), metastasis to the neck glands and extension beyond the capsule. For tumours showing well-dif- ferentiated features, extension outside the capsule, invasion of the lymphatics and metastasis to the cervical lymph nodes were also significantly less common $(\mathrm{p}=0.013)$ (see Table 4).

The associations between the pattern of growth of the neoplasm, perineural or lymphovascular infiltration, $\mathrm{N}$ staging and extracapsular spread were evaluated. The groups did not differ significantly in terms of perineural infiltration, metastasis to neck lymph nodes or extracapsular spread. Lymphovascular infiltration was a more frequent event in neoplasms exhibiting an endophytic growth pattern $(\mathrm{p}<0.05)$ (see Table 5). 
Table 5: The affect of tumor growth pattern to the perineural invasion and lymphovascular invasion, nodal metastasis and extracapsular invasion

\begin{tabular}{|c|c|c|c|c|c|c|c|c|}
\hline \multicolumn{2}{|c|}{ Tumor growth pattern } & \multicolumn{2}{|c|}{ Endophytic } & \multicolumn{2}{|c|}{ Mixed pattern } & \multicolumn{2}{|c|}{ Exophytic } & \multirow{2}{*}{$\frac{p}{0.045}$} \\
\hline Lymphovascular invasion & yes & 34 & $39.08 \%$ & 12 & $22.22 \%$ & 1 & $11.11 \%$ & \\
\hline & no & 53 & $60.92 \%$ & 42 & $77.78 \%$ & 8 & $88.89 \%$ & \\
\hline \multirow{2}{*}{ Perineural invasion } & yes & 9 & $10.34 \%$ & 4 & $7.41 \%$ & 0 & $0 \%$ & 0.529 \\
\hline & no & 78 & $89.66 \%$ & 50 & $92.59 \%$ & 9 & $100 \%$ & \\
\hline \multirow[t]{2}{*}{$\mathrm{N}$ stage } & No & 54 & $62.07 \%$ & 35 & $64.81 \%$ & 7 & $77.78 \%$ & 0.638 \\
\hline & $\mathrm{N}+$ & 33 & $37.93 \%$ & 19 & $35.19 \%$ & 2 & $22.22 \%$ & \\
\hline \multirow[t]{2}{*}{ Extracapsuler invasion } & yes & 15 & $17.24 \%$ & 8 & $14.81 \%$ & 0 & $0.00 \%$ & 0.390 \\
\hline & no & 72 & $82.76 \%$ & 46 & $85.19 \%$ & 9 & $100 \%$ & \\
\hline
\end{tabular}

Logistic regression was performed to determine which parameters determine tumour T stage. The Hosmer-Lemeshow test was used for model fit and the model was not found suitable for interpretation. $(\mathrm{p}=0.036)$ The fact that the patient's tumour was transglottic increased the likelihood of being at an advanced stage by 1.664 fold compared to supraglottic tumours $(\mathrm{p}=0.039)$. Glottic lesions were 0.069 times less likely to be advanced, compared to the supraglottic cases. In other words, supraglottic tumours carry 14.492 times higher risk of being advanced than glottic tumours.

\section{Discussion}

One of the key prognostic indicators in laryngeal carcinoma is the lymph node status. The rationale for elective neck dissection procedures in patients with neoplasms of the upper airway and digestive tract is based on the highly probable spread of metastasis via the lymphatic system (11).

Mamelle et al. were the first to suggest (in 1994) that the number of lymph nodes harbouring metastases could help inform the prognosis in head and neck malignancies (12). Currently, this is accepted as a key differentiator in estimating prognosis. Imre et al. proposed that the density of lymph node involvement may offer a more accurate measure of future prognosis. Density is assessed as the proportion of resected lymph nodes that are found to harbour tumour. Imre et al. found that, provided it is low, density acts independently to predict prognosis (3). In the present study, the relationship between histopathological appearances and metastasis to the cervical lymph nodes was evaluated. The present authors believe that increasing density of metastatic lymph node involvement reflects a raised risk of local tumour recurrence.
Published research puts the rate of perineural infiltration in head and neck squamous cell malignancies at 6-30\% (13). The American Cancer Research Committee (AJCC) classification from 2010 posits perineural invasion as a marker of worse prognosis in laryngeal carcinoma (14). PNI has also been demonstrated to have a key effect on recurrence locally or regionally as well as predicting the survival rate in head and neck malignant squamous neoplasms $(15,16,17)$. Chatzistefanou et al. asserted that perineural invasion functioned independently to influence the likelihood of cervical metastasis and regional tumour recurrence (18). Soo et al. reported a 3-year survival rate of 49 to $23 \%$ following perineural infiltration by carcinoma of the larynx (17). Johannes et al. demonstrated that perineural infiltration by laryngeal SCC has an association with local recurrence. The inward and outward growth of malignant SCC cells into the perineurium is what mediates local recurrence, it is now known (19).

McGavran et al. propose that amongst factors that raise the likelihood of metastasis to the neck is the presence of perineural infiltration (2). Yilmaz et al. claim that perineural invasion leads to a greater likelihood of metastasis within the neck and lessens survival in supraglottic malignant lesions (20). In contrast to the findings of Yilmaz et al., Özdek et al. asserted that there was no relationship between perineural invasion and cervical metastasis in supraglottic cancers $(5,20)$. Our findings, pace Özdek et $a l$., suggest a rate of $46.15 \%$ for perineural invasion, and $35.04 \%$ in patients without perineural invasion, independent of cervical metastasis. We were unable to identify any significant relationship between perineural invasion and cervical metastasis that reached the level of statistical significance $(\mathrm{p}=0.425)$.

In research published by Renato et al., it was shown 
that, whilst vascular invasion does not affect the likelihood of latent cervical metastases in patients with squamous cell malignancies of the oral cavity, perineural invasion does raise the risk of latent cervical metastases in other squamous cell neoplasms (21). Gavran et al. found that lymphovascular infiltration and lymph node metastasis were not correlated (2). However, Yilmaz et al. did correlate lymphovascular involvement with metastasis to the cervical lymph nodes, but only in supraglottic lesions, not those which were glottic or transglottic (20). Özdek et al. found that $93 \%$ of cases where lymphovascular infiltration occurred had produced metastases in the neck region, and the correlation was powerful (5). The findings in our study are in accord with the findings published by Özdek et al. In our study, the rate of cervical metastases in patients with lymphovascular invasion was $87.23 \%$ and the result was highly statistically significant $(\mathrm{p}=0.0001)$.

The key indicator of unfavourable prognosis in malignancies of the head and neck is extension of the malignancy beyond its capsule. This factor was emphasised by both Bennett et al. and Eskiizmir et al. in their writing on laryngopharynegal carcinomas $(22,23)$. However, Chirila et al. failed to correlate metastatic formation in the neck lymph nodes and rupture of the capsule (16). In the present study, cases where the neoplasm retained a well-differentiated appearance did have lower incidences of metastases in the neck nodes, lymphatic involvement and rupture of the capsule, but this relationship did not reveal statistical significance $(\mathrm{p}=0.066)$.

So far, no study has been published on the subject of how tumour staging, lymphatic infiltration and growth pattern are interrelated. Santos et al. commented that neoplasms that grow endophytically are a marker of poor

\section{References}

1. Gastardelo TS, Cunha BR, Raposo LS, et al. Inflammation and Cancer: Role of Annexin A1 and FPR2/ALX in Proliferation and Metastasis in Human Laryngeal Squamous Cell Carcinoma . PLoS One. 2014 Dec 9;9(12):e111317. doi: 10.1371/journal.pone.0111317. eCollection 2014.

2. McGavran MH, Bauer WC, Ogura JH . The incidence of cervical lymph node metastasis from epidermoid carcinoma of the larynx and their relationship to certain characteristics of the primary tumor. A study based on the clinical and pathological findings for 96 patients treated by primary en bloc laryngectomy and radical neck dissection. Cancer.1961;14:55-56. PMID: 13773928

3. Imre A, Pinar E, Dincer E, et al. Lymph Node Density in Node-Positive Laryngeal Carcinoma: Analysis of Prognostic Value for Survival. Otolaryngol Head Neck Surg. 2016 Nov;155(5):797-804. Epub 2016 May 24. DOI: 10.1177/0194599816652371 PMID: 27221573 prognosis and hence radiotherapy should be carried out as adjuvant treatment (24). The present study confirms that endophytic growth pattern is associated with lymphatic infiltration, as are tumour stages T3 and 4.

Some experts recommend watchful waiting in cases of neoplasm that are node negative clinically, alongside neck dissection as an elective procedure. In the present study, lymphatic infiltration correlated with greater risk of regional metastasis. Santos et al. and Eskiizmir et al. write that perineural and lymphatic infiltration have a key influence on the prognosis $(23,24)$. The presence of lymphovascular invasion in surgical specimens, in the authors' opinion, indicates the neck requires close follow-up for cervical lymphatic metastasis in patients who have undergone laryngectomy as sole operative procedure. Moe et al. and Eskiizmir et al. have similarly written that the number and level of lymph nodes involved in specimens obtained from neck dissection provides a prognostic clue that there is a raised risk of distant metastasis $(23,25)$. This suggests that detecting pre-lymph node dissemination is important in regulating the treatment protocol of the disease and determining its prognosis.

In conclusion, cervical lymphatic metastasis and distant organ metastasis are the most important factors influencing morbidity and survival in the long-term in cases of squamous cell carcinoma of the larynx. Histopathological findings are a very important source of information to guide the efficient evaluation of long-term follow-up and additional treatment modalities. Our study concluded that lympho-vascular invasion increases the likelihood of cervical metastasis, which may adversely impact prognosis. In such patients, additional treatment modalities such as chemoradiotherapy should be considered.

4. Iovănescu GH, Poenaru M, Doroş C, et al. Histopathological prognostic and risk factors in patients with laryngeal neoplasms. Rom J Morphol Embryol. 2013;54(4):1087-92. PMID: 24399006

5. Ozdek A, Sarac S, Akyol MU, et al. Histopathological predictors of occult lymph node metastasesin supraglottic squamous cell carcinomas. Eur Arch Otorhinolaryngol. 2000;257 :389-92. PMID: 11052252

6. Matsushita Y, Yanamoto S, Takahashi H, et al. A clinicopathological study of perineural invasion and vascular invasion in oral tongue squamous cell carcinoma. Int. J. Oral Maxillofac. Surg. 2015; 44: 543-8. DOI: 10.1016/j.ijom.2015.01.018 PMID: 25697063

7. Chirilă M, Bolboacă SD, Cosgarea M, et al. Perineural invasion of the major and minor nerves in laryngeal and hypopharyngeal cancer. Otolaryngology-Head and Neck Surgery. 2009;140:65-9. DOI: 10.1016/j. otohns.2008.10.019 PMID: 19130964 
8. Feasel AM, Brown TJ, Bogle MA, et al. Perineural invasion of cutaneous malignancies. Dermatol Surg. 2001;27:531- 42. PMID: 11442588

9. Ampil FL, Hardin JC, Peskind SP, et al. Perineural invasion in skin cancer of the head and neck: review of nine cases. J Oral Maxillofac Surg. 1995;53:34 - 8. PMID: 7799119

10. Kurtz KA, Hoffman HT, Zimmerman MB, et al. Perineural and vascular invasion in oral cavity squamous carcinoma: increased incidence on re-review of slides and by using immunohistochemical enhancement. Arch Pathol Lab Med. 2005; 129:354-9. DOI:

10. 1043/1543-2165(2005)129<354:PAVIIO>2.0.CO;2 PMID: 15737030

11. Furtado de Araújo Neto VJ, Cernea CR, Aparecido Dedivitis R, et al. Cervical metastasis on level IV in laryngeal cancer. Acta Otorhinolaryngol Ital. 2014 Feb;34(1):15-8. PMID: 24711678

12. Mamelle G, Pampurik J, Luboinski B, et al. Lymph node prognostic factors in head and neck squamous cell carcinomas. Am J Surg. 1994 Nov;168(5):494-8. PMID: 7977983

13. Fletcher KT, Gal TJ, Ebelhar AJ, et al. Prognostic indicators and survival in salvage surgery for laryngeal cancer. Head Neck. 2017;39:2021-6. DOI: 10.1002/hed.24860 PMID: 28681422

14. Mendenhall WM, Ferlito A, Takes RP, et al. Cutaneous head and neck basal and squamous cell carcinomas with perineural invasion. Oral Oncol. 2012;48:91822. DOI: 10.1016/j.oraloncology.2012.02.015 PMID: 2425152

15. Fagan JJ, Colins B, Barnes L, et al. Perineural invasion in squamous cell carcinoma of the head and neck. Arch Otolaryngol Head Neck Surg. 1998;124:640- 7. PMID: 9639472

16. Chirila M, Bolboaca SD, Cosgarea M, et al. Perineural invasion of the major and minor nerves in laryngeal and hypopharyngeal cancer. Otolaryngol Head Neck Surg. 2009;140:65-9. DOI: 10.1016/j. otohns.2008.10.019 PMID: 19130964

17. Soo KC, Carter RL, O'Brien CJ, et al. Prognostic implications of perineural spread in squamous carcinomas of the head and neck. Laryngoscope. 1986;96: 1145-8. PMID: 3762289
18. Chatzistefanou I, Lubek J, Markou K, et al. The role of neck dissection and postoperative adjuvant radiotherapy in $\mathrm{cN} 0$ patients with PNI-positive squamous cell carcinoma of the oral cavity. Oral Oncol. 2014;50:753-8. DOI: 10.1016/j.oraloncology.2014.05.005 PMID: 24909939

19. Ballantyne AJ, McCarte AB, Ibanez ML. The extension of cancer of the head and neck through peripheral nerves. Am J Surg. 1963;36:269-75. PMID: 14070757

20. Yilmaz T, Turan E, Gürsel B, et al. Positive surgical margins in cancer of the larynx, Eur Arch Otorhinolaryngol. 2001;258:188-91. PMID: 11407451

21. Bittar RF, Ferraro HP, Ribas MH, et al. Predictive factors of occult neck metastasis in patients with oral squamous cell carcinoma. Braz J Otorhinolaryngol. 2016;82:543-7. DOI: 10.1016/j.bjorl.2015.09.005 PMID: 26749457

22. Bennett SH, Futrell JW, Roth JA, et al. Prognostic significance of histologic host response in cancer of the larynx or hypopharynx. Cancer. 1971;28:1255-65. PMID: 5125672

23. Eskiizmir G, Tanyeri Toker G, Celik O, et al. Predictive and prognostic factors for patients with locoregionally advanced laryngeal carcinoma treated with surgical multimodality protocol. Eur Arch Otorhinolaryngol. 2017 Mar;274(3):1701-1711. doi: 10.1007/s00405-016-4411-9. Epub 2016 Dec 10. PMID: 27942895

24. Santos TS, Estêvão R, Antunes L, et al. Clinical and histopathological prognostic factors in locoregional advanced laryngeal cancer. J Laryngol Otol. 2016 Oct;130(10):948-953. doi: 10.1017/S002221511600880X. PMID:27774922

25. Moe K, Wolf GT, Fisher SG,et al. Regional metastases in patients with advanced laryngeal cancer. Department of Veterans Affairs Laryngeal Cancer Study Group. Arch Otolaryngol Head Neck Surg. 1996 Jun;122(6):644-8. PMID: 8639297

This is an open access article distributed under the terms of the Creative Commons Attribution-NonCommercial-NoDerivs 3.0 Unported (CC BY- NC-ND3.0) Licence (http://creativecommons.org/licenses/by-nc-nd/3.0/) which permits unrestricted noncommercial use, distribution, and reproduc- tion in any medium, provided the original work is properly cited.

Please cite this article as: Belli S., Yıldırım M., Kaya F.E., Bilece T., Oktay M.F., How Do Histopathological Findings Relate To Cervical Lymph Node Metastasis In Laryngeal Cancer? A Retrospective Study And Literature Review. ENT Updates 2019;9(1): 11-17 